\title{
Caracterização de blocos cerâmicos acústicos produzidos com incorporação de lodo de lavanderia têxtil
}

\author{
Characterization of acoustic ceramic blocks produced \\ with incorporating textile laundry sludge
}

\begin{abstract}
Thiago Morais de Castro', Célia Regina Granhen Tavares², Aline Lisot ${ }^{3}$, Oswaldo Teruo Kaminata ${ }^{4}$
\end{abstract}
\begin{abstract}
RESUMO
Características físicas (absorção de água), mecânicas (resistência à compressão), de toxicidade e de superfície (microscopia eletrônica de varredura) foram avaliadas em blocos cerâmicos acústicos, fabricados por meio do processo de solidificação/estabilização (S/E), a partir da incorporação de lodo proveniente de estação de tratamento de efluentes têxteis. Os blocos cerâmicos acústicos foram produzidos com incorporação de 5, 10, 15, 20, 25, 30 e 35\% de lodo têxtil na massa de argila, bem como o bloco controle. Os resultados indicaram a porcentagem de $20 \%$ de lodo como o limite para fornecer material com características de acordo com os padrões estabelecidos pela legislação brasileira. O processo de S/E foi eficiente no aproveitamento/tratamento do lodo têxtil, uma vez que permitiu a imobilização dos poluentes na massa de argila, os quais não foram lixiviados, tampouco solubilizados.
\end{abstract}

Palavras-chave: bloco cerâmico acústico; solidificação/estabilização; lodo de lavanderia têxtil.

\begin{abstract}
Physical characteristics (water absorption), mechanical (compression length), of toxicity and surface (scanning electron microscopy) were evaluated in acoustic ceramic blocks, manufactured by the process of solidification/stabilization (S/S) from the incorporation of sludge from a textile wastewater treatment plant. Acoustic ceramic blocks were produced by incorporating of $5,10,15,20,25,30$ and $35 \%$ of textile sludge in the clay mass/material as well as the control block. The results indicated the percentage of $20 \%$ of sludge, as the limit to provide materials with good characteristics of accordance with the standards established by Brazilian law. The S/S process was efficient in the recovery/treatment of the textile sludge, as it allowed the immobilization of pollutants in the clay mass/material, which have not been leached, neither solubilized.
\end{abstract}

Keywords: acoustic ceramic block; solidification/stabilization; textile laundry sludge.

\section{INTRODUÇÃO}

Nas estações de tratamento de efluentes de lavanderias industriais, geralmente é gerada, durante o tratamento primário (físico-químico) ou secundário (biológico), grande quantidade de resíduo sólido, o lodo (HEREK et al., 2010). Este resíduo muitas vezes tem destino final inadequado, ficando exposto ao ambiente, contaminando-o, ou há um alto custo para as empresas destinarem de forma adequada o lodo para aterros industriais licenciados.
O procedimento que envolve a solidificação/estabilização (S/E) de resíduos sólidos industriais em matrizes sólidas, tais como argila cerâmica, argamassas de cimento e de concreto, produzindo-se materiais utilizáveis na construção civil, consiste em alternativa de tratamento/ reaproveitamento de resíduos. A utilização da argila como agente solidificador no tratamento de resíduos passou a ser investigada a partir da constatação de que os processos clássicos à base de cimento e cal não eram eficientes no tratamento de resíduos com alto teor de materiais

'Doutorando em Engenharia Agrícola pela Universidade Estadual do Oeste do Paraná (UNIOESTE). Mestre em Engenharia Urbana pela Universidade Estadual de Maringá (UEM). Professor do Departamento Acadêmico de Engenharia Ambiental da Universidade Tecnológica Federal do Paraná (UTFPR) - Campo Mourão (PR), Brasil.

${ }^{2}$ Pós-Doutora em Engenharia Ambiental pela Université Montpellier II - Montpellier, França. Doutora em Engenharia Química pela Universidade Federal do Rio de Janeiro (UFRJ). Professora Titular do Departamento de Engenharia Química da UEM - Maringá (PR), Brasil.

${ }^{3}$ Doutora em Engenharia Civil pela Universidade Estadual de Campinas (UNICAMP). Professora Adjunta do Departamento de Engenharia Civil da UEM - Maringá (PR), Brasil. ${ }^{4}$ Mestre em Engenharia Urbana pela Universidade Estadual de Maringá (UEM). Professor do Departamento de Engenharia Civil da UEM - Maringá (PR), Brasil. Endereço para correspondência: Thiago Morais de Castro - Via Rosalina Maria dos Santos, 1.233 - $87301-899$ - Caixa Postal 271 - Campo Mourão (PR), Brasil -

E-mail: thiagocastro@utfpredu.br

Recebido: 12/04/12 - Aceito: 11/12/14 - Reg. ABES: 88966 
orgânicos (VIEIRA et al., 2007). Os benefícios do uso de resíduos como aditivos cerâmicos incluem, além da imobilização de metais pesados na matriz queimada, a oxidação da matéria orgânica e a destruição de qualquer organismo patogênico durante o processo de queima.

$\mathrm{Na}$ última década vários estudos comprovaram a potencialidade do aproveitamento de resíduos sólidos industriais como matéria-prima para a fabricação, principalmente, de material cerâmico, como é o caso dos trabalhos de Paixão et al. (2008), que estudaram a incorporação de lodo gerado em estação de tratamento de água em massa cerâmica argilosa, para fabricação de material para construção civil; Moreira et al. (2001), que estudaram a incorporação de lodo têxtil em argila, para reaproveitamento na construção civil; Oliveira et al. (2004), que verificaram, por meio da determinação das características de lodo gerado em estação de tratamento de água, a possibilidade de sua aplicação na incorporação em massa de cerâmica vermelha, obtendo bons resultados de aplicabilidade, entre outros.

Outro problema ambiental comum nas metrópoles brasileiras é o ruído gerado, principalmente pelo tráfego de veículos no meio urbano, o qual é capaz de provocar efeitos danosos à saúde da população. Segundo Lisot (2008), é interessante realizar intervenções no ambiente, com o intuito de diminuir a intensidade dos sons que atingem o receptor. A utilização de barreiras acústicas tem se difundido como uma alternativa para o controle de ruído.

Alguns pesquisadores (LISOT, 2008; BISTAFA, 2011; SANTOS, 2005; SOUZA et al., 2006) acreditam que uma das formas de melhorar o desempenho de barreiras acústicas é utilizar, por exemplo, blocos absorventes acústicos (ressoadores) na sua execução. Os ressoadores são peças que têm a capacidade de absorver sons em frequências específicas, principalmente as mais baixas, conforme o seu dimensionamento. No entanto, há necessidade de se avaliar as características físicas, mecânicas e de toxicidade desses materiais, com o intuito de verificar o atendimento aos padrões estabelecidos na legislação, ao se fazer a substituição de matérias-primas constituintes por resíduos industriais não inertes.

Avaliou-se a incorporação de lodo de lavanderias industriais têxteis por meio do processo de solidificação/estabilização (S/E) na fabricação de blocos cerâmicos acústicos em escala reduzida de 1:5, em relação aos blocos fabricados em escala real. A avaliação do processo citado teve como objetivo caracterizar os blocos em função dos fatores: resistência à compressão, índice médio de absorção de água, análise da porosidade por meio de microscopia eletrônica de varredura (MEV), análises químicas dos extratos lixiviados e solubilizados dos blocos.

\section{METODOLOGIA}

A argila cerâmica utilizada neste estudo foi extraída da jazida formada por sedimentação aluvial, localizada próximo às margens do Rio Ivaí no município de Japurá (PR). A amostra de argila foi caracterizada quanto ao teor de umidade e à matéria orgânica total (KIEHL, 1979), ao $\mathrm{pH}$ (APHA, 2005), à análise granulométrica, conforme a NBR 7181 (1984), ao limite de plasticidade e ao índice de plasticidade, seguindo a NBR 7180 (1984), ao limite de liquidez, de acordo com a NBR 6459 (1984), e à massa específica, seguindo a NBR 6508 (1984).

Foram coletados lodos de 12 lavanderias industriais da região de Maringá (PR). Os lodos apresentavam características semelhantes entre si por serem originados de um mesmo ramo industrial. Esses resíduos passaram por processo de secagem e encontravam-se prontos para a destinação final em aterros industriais.

As etapas do processo de fabricação dos blocos consistiram em: preparação das matérias-primas (moagem do lodo e da argila, mistura, correção da umidade e homogeneização), conformação (formação ou moldagem dos blocos), secagem e processamento térmico de queima.

A mistura homogênea de lodo passou por moagem, utilizando-se moinho cilíndrico de barras, com capacidade para $30 \mathrm{~kg}$, adaptado com motor elétrico de $2 \mathrm{hp}$ e redutor para 30 rotações por minuto. Em seguida, a mistura foi peneirada em malha de 2,4 $\mathrm{mm}$, para evitar eventuais obstruções na boquilha da extrusora durante a produção dos blocos cerâmicos.

A caracterização do lodo foi realizada por meio dos seguintes parâmetros: massa específica, de acordo com a NBR 6508 (1984), teor de umidade e matéria orgânica total (KIEHL, 1979) e pH (EMBRAPA, 1997). A mistura de lodo foi classificada por Kaminata (2008) como sendo classe II-A (não perigoso e não inerte), conforme a NBR 10004 (2004). Foram utilizadas a NBR 10005 (2004) para a obtenção do extrato lixiviado e a NBR 10006 (2004) para a obtenção do extrato solubilizado, ambas normas da Associação Brasileira de Normas Técnicas (ABNT).

Foram produzidas amostras de blocos cerâmicos acústicos em escala reduzida em 1:5, utilizando formulações com incorporação em massa seca de 10, 15, 20, 25, 30 e 35\% de lodo na massa seca de argila cerâmica. Além disso, foram produzidos blocos controle, ou seja, fabricados somente com argila.

O bloco cerâmico acústico utilizado na pesquisa, com formato característico, foi desenvolvido por Lisot (2008), tendo em vista a necessidade de, no cálculo da frequência de oscilação (frequência de maior absorção), atingir-se um valor entre 125 e $250 \mathrm{~Hz}$ para um bloco absorvedor acústico em escala real. Nos resultados obtidos por Lisot (2008), observou-se que em torno da frequência de $200 \mathrm{~Hz}$ ocorria um aumento significativo da absorção sonora dos ressoadores. Esta frequência de oscilação aproximou-se daquela calculada quando do dimensionamento do ressoador em escala real.

Para a fabricação dos blocos cerâmicos acústicos, a argila beneficiada era adicionada à mistura do lodo e, em seguida, adicionava-se água até formar uma massa pastosa, que era introduzida na extrusora. Na saída da extrusora, a massa em forma de barra era cortada com fios de aço reguláveis na dimensão do bloco cerâmico acústico projetado 
por Lisot (2008) (as dimensões completas do bloco não são citadas neste artigo, pois o estudo está em processo de obtenção de patente, encaminhada ao Instituto Nacional de Propriedade Industrial - INPI).

Após a extrusão e o corte dos blocos (Figura 1), os objetos foram armazenados em ambiente fechado e pouco ventilado, onde permaneceram secando por, no mínimo, sete dias (Figura 2). O tempo de secagem é necessário para os blocos adquirirem retração lenta e gradativa, eliminando a água e mantendo a estrutura sem fissuras durante a queima.

O forno utilizado na queima foi do tipo Hoffman e o processo foi realizado em uma olaria industrial na cidade de Japurá (PR). A queima dos blocos ocorreu em temperatura média de $930^{\circ} \mathrm{C}$. Na Figura 3 apresenta-se uma peça de bloco resultante do processo descrito.

Após a queima dos blocos cerâmicos acústicos, os objetos foram caracterizados conforme procedimentos descritos na NBR 15270-2 (2005) e na NBR 15270-3 (2005) da ABNT. Para o ensaio de resistência característica à compressão nas amostras dos blocos acústicos, foi utilizada a prensa modelo EMU 100, com capacidade para 20.000 kg. Para

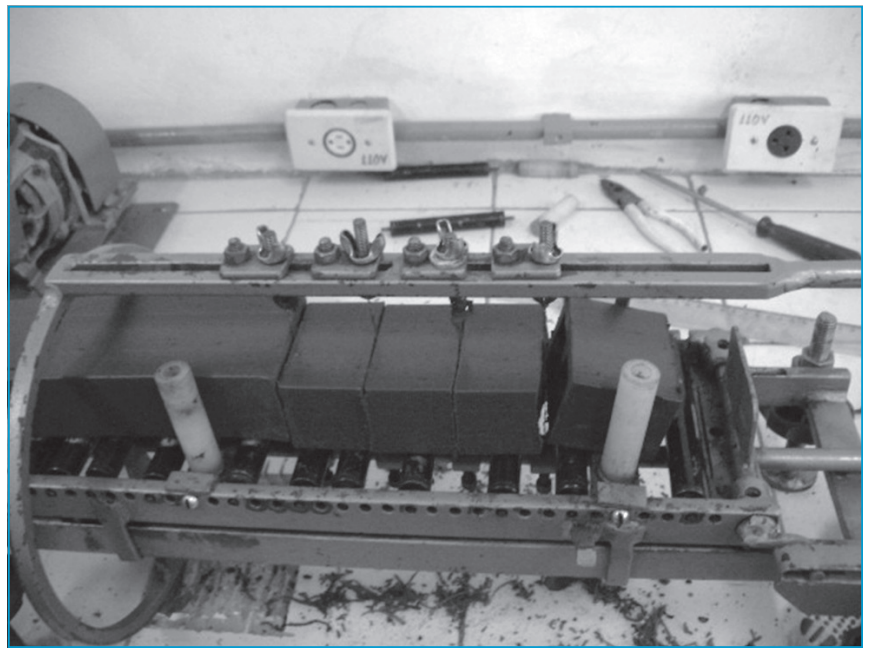

Figura 1 - Corte da barra após a extrusão.

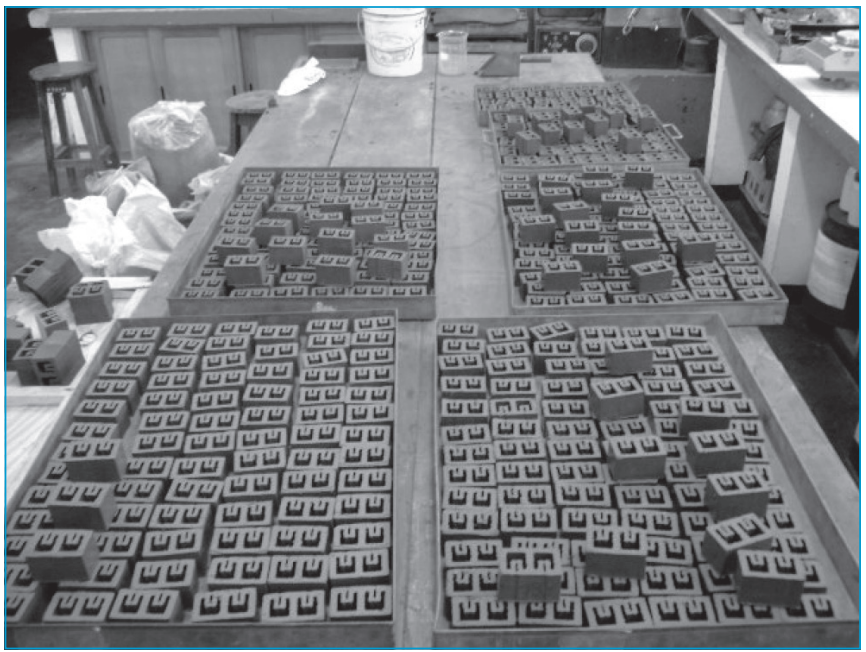

Figura 2 - Blocos cerâmicos sendo secos em ambiente isolado. o ensaio de absorção de água, utilizou-se a estufa de secagem Quimis, que manteve temperatura entre $105 \pm 5^{\circ} \mathrm{C}$, e a balança Gerraka, modelo 2000, com sensibilidade de $1,0 \mathrm{~g}$.

A caracterização dos blocos cerâmicos referente à análise de superfície foi realizada por meio do ensaio de MEV. O MEV permitiu a observação e análise microestrutural da massa cerâmica. Para o caso deste estudo, a MEV foi meramente ilustrativa, para visualização das conformações estruturais de cada amostra de bloco cerâmico nas diferentes formulações de lodo empregado na massa de argila. Utilizou-se, para essa finalidade, o MEV modelo SS-550, da marca Shimadzu.

Também foram realizados ensaios de lixiviação e solubilização dos blocos cerâmicos acústicos, ações que visaram simular o comportamento do bloco submetido a uma situação crítica de utilização, o que poderia provocar a contaminação do solo e do lençol freático com o processo de lixiviação e solubilização de elementos tóxicos incorporados nos blocos cerâmicos. A obtenção dos extratos lixiviados e solubilizados das amostras dos blocos cerâmicos foi realizada de acordo com os procedimentos das normas da ABNT, NBR 10005 (2004) e NBR 10006 (2004). Para a determinação dos elementos químicos dos extratos lixiviados e solubilizados, foi utilizado o espectrômetro de absorção atômica modelo SpectrAA 50B, da marca Varian.

\section{RESULTADOS E DISCUSSÃO}

\section{Características do lodo e da argila cerâmica utilizada no experimento}

A Tabela 1 apresenta os resultados da caracterização do lodo e da argila utilizada na fabricação dos blocos cerâmicos acústicos.

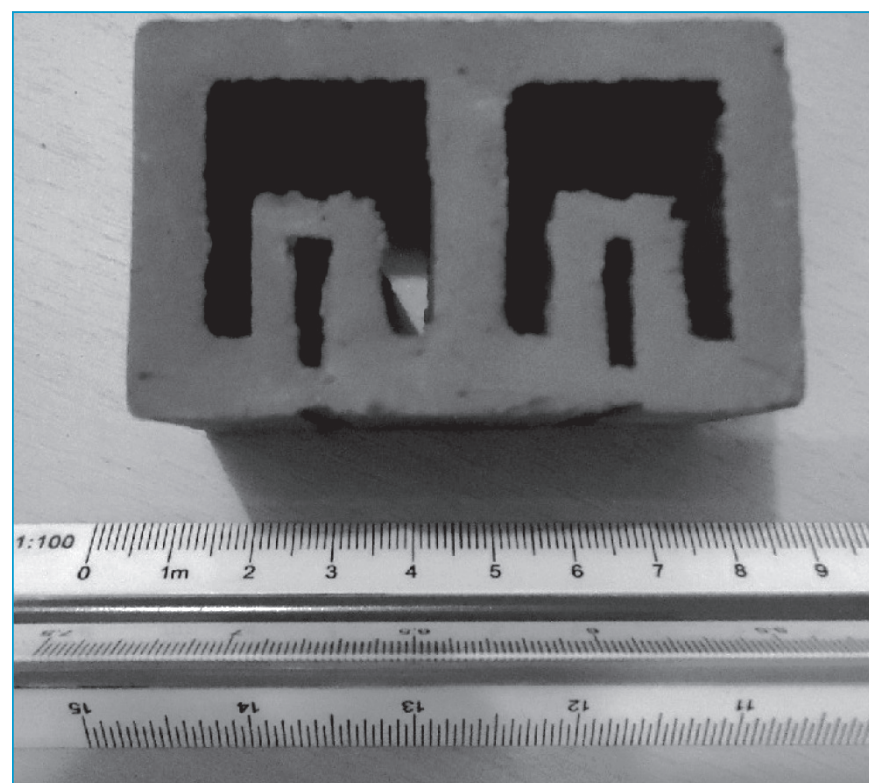

Figura 3 - Bloco cerâmico acústico fabricado. 
As características da argila dependem da sua formação geológica e da localização da extração. A argila estudada é proveniente da Bacia Hidrográfica do Rio Ivaí, norte do Estado do Paraná, onde predominam rochas sedimentares, folhetos, arenitos e calcários, de acordo com dados obtidos em MINEROPAR (2006).

$\mathrm{O}$ valor de $\mathrm{pH}$ da argila analisada ficou em torno de 5,0. De acordo com Thomas (1996), valores de $\mathrm{pH}$ do solo de 4,0 a 6,0 indicam a presença de alumínio trivalente em solos minerais e até em certos solos orgânicos.

Observam-se, na Tabela 1, quantidades significativas de alumínio e ferro no lodo, muito provavelmente provenientes dos elementos floculantes utilizados no processo de tratamento de efluentes das lavanderias industriais, e de sódio proveniente do agente antifungo e do eletrólito utilizado no tingimento durante o processo de produção têxtil.

Na Tabela 2 são apresentados os valores da distribuição do tamanho das partículas e os limites de consistência da argila utilizada para a fabricação dos blocos cerâmicos acústicos. $\mathrm{O}$ termo consistência é utilizado para designar as manifestações das forças físicas de coesão entre partículas do solo e de adesão entre as partículas e outros materiais.

Verifica-se, na Tabela 2, um limite de liquidez (LL) de 57\%, o que indica uma argila de alta compressibilidade, tornando a massa mais densa durante extrusão. De acordo com Campos et al. (1999), o LL superior

Tabela 1 - Caracterização do lodo misto e da argila.

\begin{tabular}{l|c|c}
\hline Parâmetros & Lodo & Argila \\
\hline Aspecto & Levemente úmido & Seca \\
\hline $\mathrm{pH}$ & 7,70 & 5,00 \\
\hline Matéria orgânica total (\%) & 43,70 & 5,33 \\
\hline Umidade (\%) & 20,01 & 5,73 \\
\hline Massa específica (g.cm-3) & 1,95 & 2,78 \\
\hline Classe - NBR 10004 (2004) & $2-\mathrm{A}^{1}$ & - \\
\hline Alumínio (mg/kg) & $6,3 \times 10^{4}$ & - \\
\hline Chumbo (mg/kg) & 174,7 & - \\
\hline Cobre $(\mathrm{mg} / \mathrm{kg})$ & 287,5 & - \\
\hline Cromo $(\mathrm{mg} / \mathrm{kg})$ & 195,0 & - \\
\hline Ferro $(\mathrm{mg} / \mathrm{kg})$ & $3,5 \times 10^{4}$ & - \\
\hline Manganês $(\mathrm{mg} / \mathrm{kg})$ & $1.106,1$ & - \\
\hline Sódio $(\mathrm{mg} / \mathrm{kg})$ & $3,3 \times 10^{4}$ & - \\
\hline Zinco $(\mathrm{mg} / \mathrm{kg})$ & 294,4 & - \\
\hline Prata $(\mathrm{mg} / \mathrm{kg})$ & n.d. & - \\
\hline Bário $(\mathrm{mg} / \mathrm{kg})$ & n.d. & - \\
\hline
\end{tabular}

n.d.: não detectado.

Fonte: Kaminata (2008)

Tabela 2 - Características da argila cerâmica.

\begin{tabular}{l|c} 
Características & $\%$ \\
\hline Argila & 50 \\
\hline Silte & 30 \\
\hline Areia fina & 18 \\
\hline Areia média & 2 \\
\hline$L P$ & 23 \\
\hline$L L$ & 57 \\
\hline$I P$ & 34 \\
\hline
\end{tabular}

LP: limite de plasticidade; LL: limite de liquidez; IP: índice de plasticidade. a 50\% indica que a argila apresenta alta compressibilidade. Para moldagem de tijolos furados por extrusão, as faixas de LL e índice de plasticidade (IP) recomendadas para argilas plásticas correspondem a: LL variando de 26,5 a $71,6 \%$, e IP, de 4,0 a $47,7 \%$.

\section{Resistência característica à compressão dos blocos cerâmicos acústicos}

Neste ensaio, verificou-se a capacidade de carga que os blocos cerâmicos acústicos de todas as formulações suportavam quando submetidos a forças aplicadas na direção do esforço que o bloco deve suportar durante o seu emprego, ou seja, perpendicular ao comprimento e na face destinada ao assentamento.

As amostras de blocos, que possuem funções estruturais, como é o caso dos blocos cerâmicos acústicos, devem atender ao requisito mínimo de 3,0 MPa, de acordo com a NBR 15270-2 (2005). A Figura 4 apresenta a evolução da resistência característica à compressão $\left(\mathrm{f}_{\mathrm{bk}}\right)$ dos blocos em função do teor de lodo incorporado à massa de argila. Na Tabela 3 são apresentados os valores obtidos de resistências características à compressão e a análise estatística em termos de desvio padrão e variância.

Verifica-se que em todas as proporções utilizadas os valores de $f_{b k}$ dos blocos cerâmicos acústicos produzidos atenderam ao limite mínimo especificado na NBR 15270-2 (2005). Esses valores devem ser considerados como os valores de referência. O não atendimento aos parâmetros normativos mínimos indica que paredes construídas com esses blocos poderão apresentar problemas estruturais, como rachaduras, $\mathrm{e}$, consequentemente, oferecerão riscos de desabamento da construção.

Observa-se que com o aumento da incorporação de lodo há redução dos valores de resistência à compressão média $\left(f_{b m}\right)$ dos blocos. Essa relação está associada ao aumento da porosidade formada na queima dos blocos

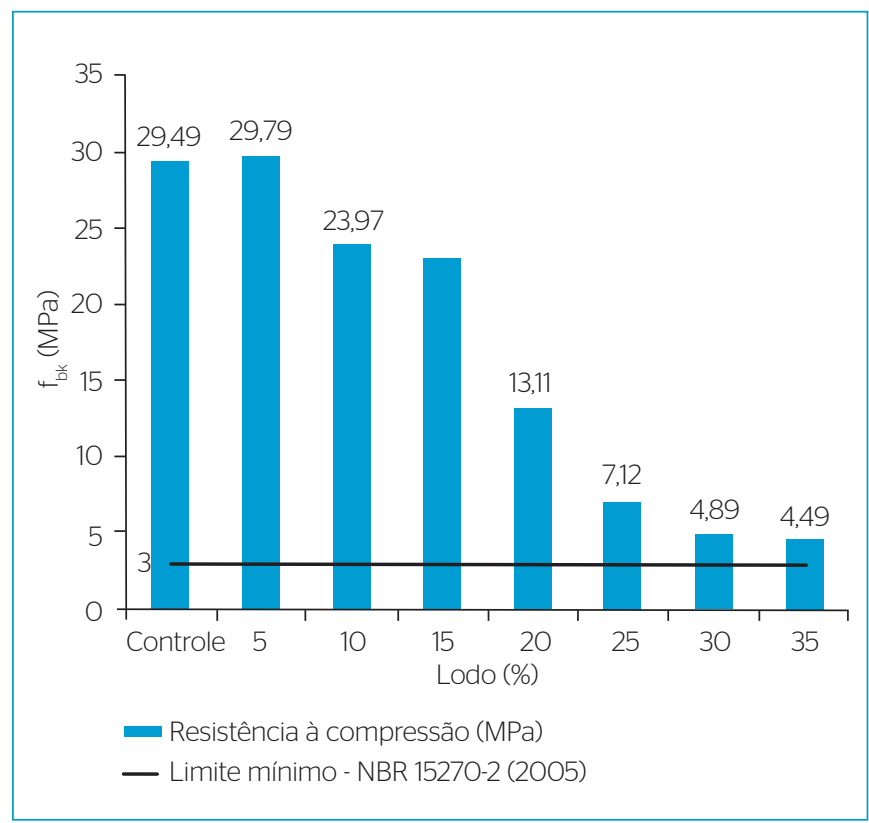

Figura 4 - Resistências característica à compressão dos blocos cerâmicos acústicos. 
cerâmicos acústicos, devido à volatilização da matéria orgânica presente no lodo durante o processo de queima. O teor de matéria orgânica no lodo é um parâmetro que influencia na qualidade final dos blocos cerâmicos, pois resulta diretamente na proporção da porosidade. Notam-se, por meio dos resultados de desvio padrão, pequenos valores para todas as formulações, o que garante uma confiabilidade dos resultados obtidos.

\section{Índice de absorção de água}

Os ensaios de absorção de água dos blocos cerâmicos têm como objetivo verificar o índice de absorção de água no período de 24 horas a temperatura ambiente. A Figura 5 ilustra graficamente a evolução dos índices médios de absorção de água, assim como os limites mínimos e máximos estabelecidos de acordo com a NBR 15270-3 (2005). A Tabela 4 apresenta os valores obtidos de índices de absorção de água e a análise estatística em termos de desvio padrão e variância.

Em geral, observa-se que o aumento do teor de lodo aumentou o índice de absorção de água, com exceção do bloco cerâmico com 5\% de lodo, cujo valor médio ficou abaixo do limite mínimo estabelecido pela NBR 15270-3 (2005). O bloco cerâmico acústico com adição de 25\% de lodo absorveu uma quantidade de água muito próxima ao limite máximo recomendado pela norma; dessa forma, não seria recomendável a utilização dessa quantidade de lodo em substituição à argila, uma vez que é prudente adotar uma margem de segurança para materiais que serão fabricados em escala industrial.

O aumento do índice de absorção de água está associado ao aumento da porosidade presente nos blocos, devido à volatilização da grande quantidade de matéria orgânica, aproximadamente $44 \%$, presente no lodo. Verifica-se uma tendência de aumento da absorção de água com o aumento da quantidade de lodo incorporada nos blocos cerâmicos. A análise dos resultados de desvio padrão e variância permite observar pequenas variações nos valores obtidos, o que garante uma maior confiabilidade nesses resultados.

\section{Microscopia eletrônica de varredura}

Na Figura 6 são apresentadas as micrografias obtidas por meio da MEV de partes dos blocos cerâmicos acústicos produzidos.

A quantidade de poros está diretamente relacionada à resistência à compressão e ao índice de absorção de água, ou seja, quanto maior a quantidade de poros, menor será a resistência à compressão e maior será o índice de absorção de água. De certa forma, esses resultados foram comprovados pelas análises de resistência à compressão e de absorção de água. A tendência ao surgimento de mais vazios com a incorporação de lodo muito provavelmente se deve à volatilização da matéria orgânica durante a queima, à medida que se acrescentou lodo na composição da massa cerâmica.

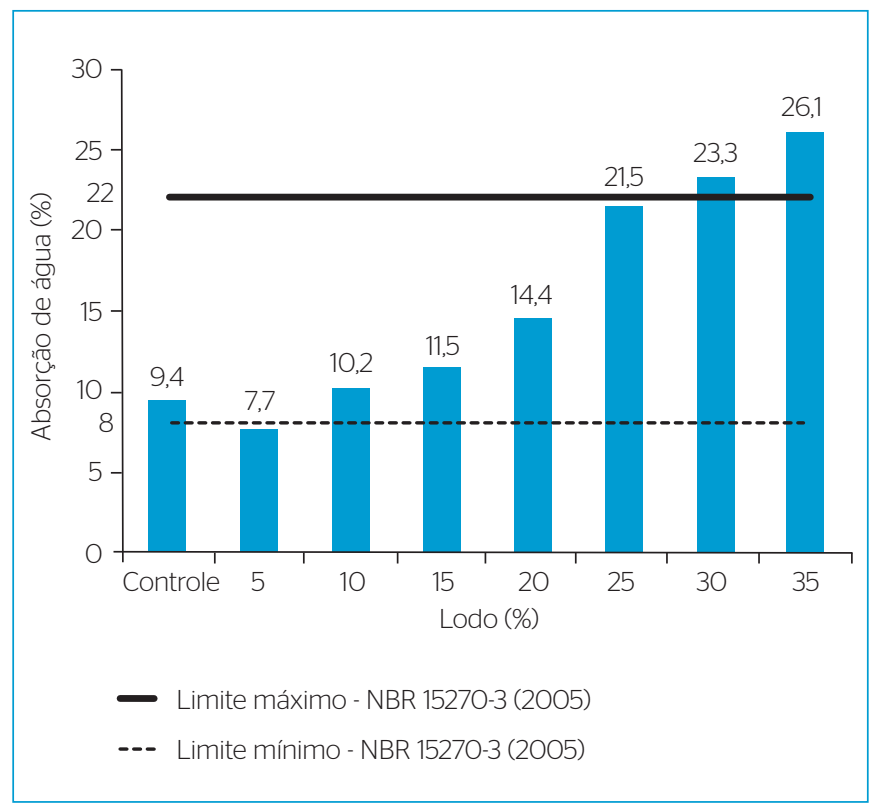

Figura 5 - Índice médio de absorção de água em amostras dos blocos cerâmicos.

Tabela 3 - Valores de resistência à compressão e resultados estatísticos ( $n=20)$.

\begin{tabular}{l|c|c|c|c|c|c|c|c}
\hline Parâmetros & Controle & $5 \%$ de lodo & $10 \%$ de lodo & $15 \%$ de lodo & $20 \%$ de lodo & $25 \%$ de lodo & $30 \%$ de lodo & $35 \%$ de lodo \\
\hline$f_{\text {bk..est }}(\mathrm{MPa})$ & 28,97 & 28,21 & 22,89 & 23,02 & 12,62 & 7,12 & 4,89 & 4,49 \\
\hline $\mathrm{f}_{\text {bm }}(\mathrm{MPa})$ & 34,46 & 34,22 & 26,71 & 26,65 & 15,96 & 9,05 & 6,55 & 6,08 \\
\hline $\mathrm{f}_{\text {bk }}(\mathrm{MPa})$ & 29,49 & 29,79 & 23,97 & 23,02 & 13,11 & 7,12 & 4,89 & 4,49 \\
\hline $\mathrm{f}_{\text {bma }}(\mathrm{MPa})$ & 39,20 & 38,30 & 31,04 & 30,25 & 18,76 & 11,06 & 8,19 & 7,78 \\
\hline $\mathrm{f}_{\text {bmi }}(\mathrm{MPa})$ & 29,79 & 29,79 & 23,97 & 23,02 & 13,11 & 6,64 & 3,44 & 3,44 \\
\hline$\sigma^{2}$ & 8,2 & 7,3 & 4,9 & 4,6 & 4,6 & 1,1 & 1,1 & 1,0 \\
\hline$\sigma$ & 2,9 & 2,7 & 2,2 & 2,2 & 2,1 & 1,1 & 1,1 & 1,0 \\
\hline
\end{tabular}

$\mathrm{f}_{\text {bkest }}$ resistência característica à compressão estimada da amostra (MPa); $\mathrm{f}_{\mathrm{bm}}$ : resistência à compressão média (MPa); $\mathrm{f}_{\mathrm{bk}}$ : resistência característica à compressão (MPa); $\mathrm{f}_{\mathrm{bmà}}$ : resistência à compressão máxima (MPa); $\mathrm{f}_{\mathrm{bm} \text { : }}$ resistência à compressão minima (MPa); $\sigma^{2}$ : variância; $\sigma$ : desvio padrão.

Tabela 4 - Índices de absorção de água e resultados estatísticos ( $n=20)$.

\begin{tabular}{|c|c|c|c|c|c|c|c|c|}
\hline Parâmetros & Controle & $5 \%$ de lodo & $10 \%$ de lodo & $15 \%$ de lodo & $20 \%$ de lodo & $25 \%$ de lodo & $30 \%$ de lodo & $35 \%$ de lodo \\
\hline Índice médio (\%) & 9,4 & 7,7 & 10,2 & 11,5 & 14,4 & 21,5 & 23,3 & 26,1 \\
\hline Índice máximo (\%) & 10,4 & 8,5 & 11,8 & 12,8 & 15,8 & 22,1 & 24,1 & 26,8 \\
\hline Índice mínimo (\%) & 6,9 & 7,2 & 9,3 & 10,4 & 12,5 & 20,9 & 22,7 & 25,8 \\
\hline Variância $\left(\sigma^{2}\right)$ & 0,91 & 0,13 & 0,33 & 0,38 & 0,95 & 0,12 & 0,12 & 0,08 \\
\hline Desvio padrão $(\sigma)$ & 0,95 & 0,36 & 0,57 & 0,62 & 0,98 & 0,34 & 0,35 & 0,29 \\
\hline
\end{tabular}



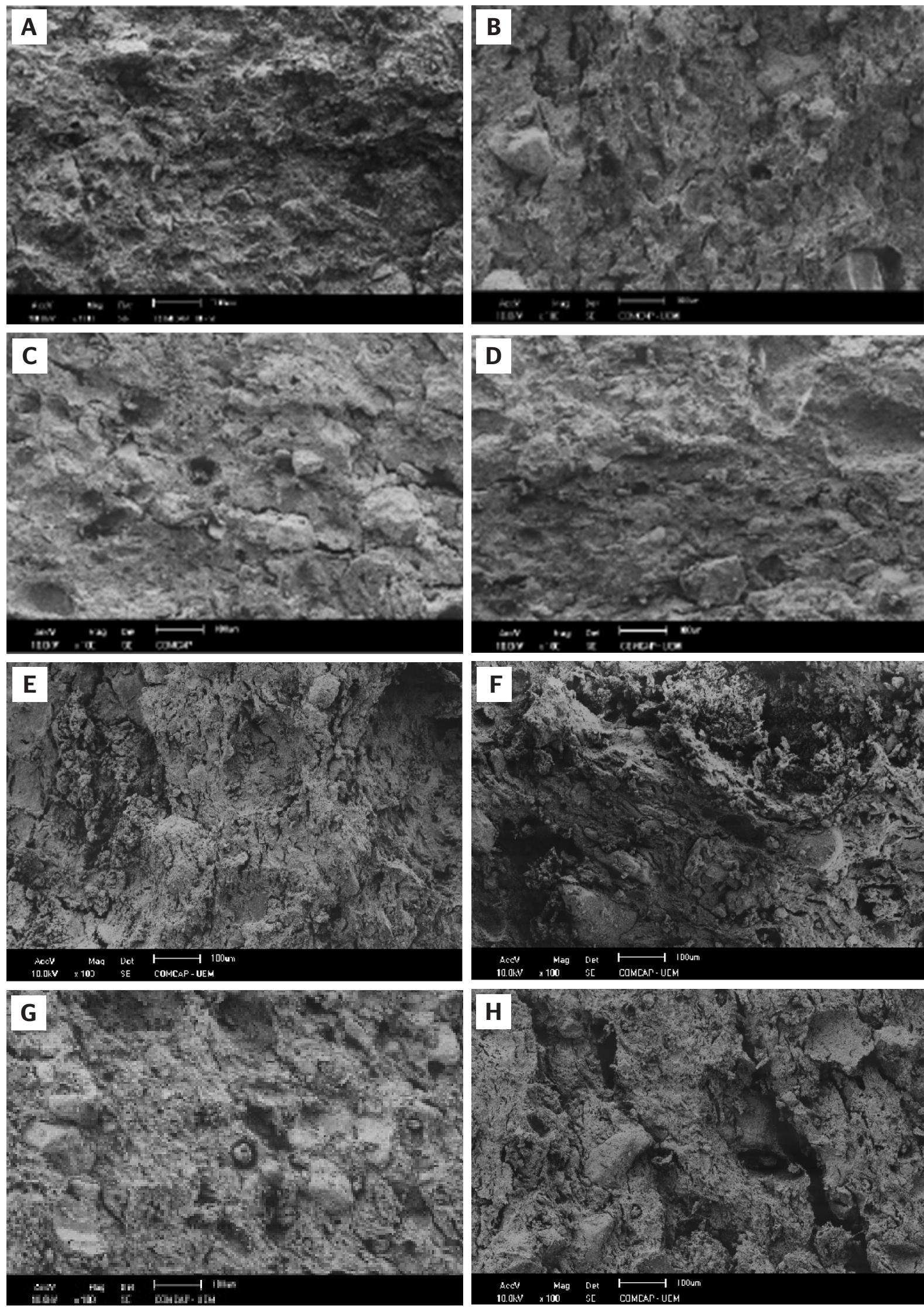

Figura 6 - Imagens obtidas pela microscopia eletrônica de varredura em estruturas de blocos cerâmicos acústicos (100x). (A) Bloco controle: (B) bloco com 5\% de lodo; (C) bloco com 10\% de lodo; (D) bloco com 15\% de lodo; (E) bloco com $20 \%$ de lodo; (F) bloco com $25 \%$ de lodo; (G) bloco com $30 \%$ de lodo; $(\mathrm{H})$ bloco com $35 \%$ de lodo. 
Verificam-se, nas imagens obtidas com ampliação de 100 vezes, diferentes estruturas formadas nas amostras de blocos cerâmicos produzidos com 5, 10, 15, 20, 25, 30 e 35\% de lodo. Pode-se notar que a estrutura da massa cerâmica apresentou maior quantidade e diversidade de poros à medida que se acrescentou o resíduo em sua composição.

\section{Análises químicas dos blocos cerâmicos acústicos (análise de toxicidade)}

Nas Tabelas 5 e 6 são apresentados os resultados das análises dos extratos lixiviado e solubilizado realizados no bloco cerâmico controle, bem como naqueles fabricados com até $20 \%$ de lodo, em substituição à argila.

Por não terem lixiviado nenhum elemento acima das concentrações permitidas relacionadas no Anexo F da NBR 10004 (2004), Tabela 5, pode-se considerar que as amostras de todos os blocos cerâmicos acústicos, após seu período de utilização, poderão ser classificadas como não perigosas.

Os extratos solubilizados das amostras de blocos cerâmicos acústicos não apresentaram elementos químicos solubilizados acima do limite estabelecido pelo Anexo G da NBR 10004 (2004), Tabela 6. Assim, os blocos cerâmicos acústicos apresentaram-se como inertes, ou seja, os elementos químicos presentes no lodo ficaram estabilizados na massa de argila dos blocos cerâmicos.

\section{CONCLUSÕES}

A partir das análises dos resultados experimentais pode-se concluir que, com relação à resistência característica à compressão, os blocos cerâmicos acústicos fabricados em todas as formulações apresentaram valores acima do mínimo exigido pela norma, que é de 3,0 MPa. Conforme os resultados do ensaio de absorção de água dos blocos, a produção de blocos até a incorporação máxima de $25 \%$, com exceção do bloco com incorporação de $5 \%$ de lodo, apresentou-se dentro dos limites estabelecidos nas normas vigentes. No entanto, é interessante observar que a proporção máxima de $20 \%$ pode levar à obtenção de um produto com maior garantia de qualidade técnica; sendo assim, tal formulação foi considerada a máxima recomendada.

Os resultados dos ensaios químicos de lixiviação e solubilização dos extratos dos blocos cerâmicos acústicos produzidos em escala 1:5, com

Tabela 5 - Características tóxicas dos blocos cerâmicos acústicos (ensaio de lixiviação).

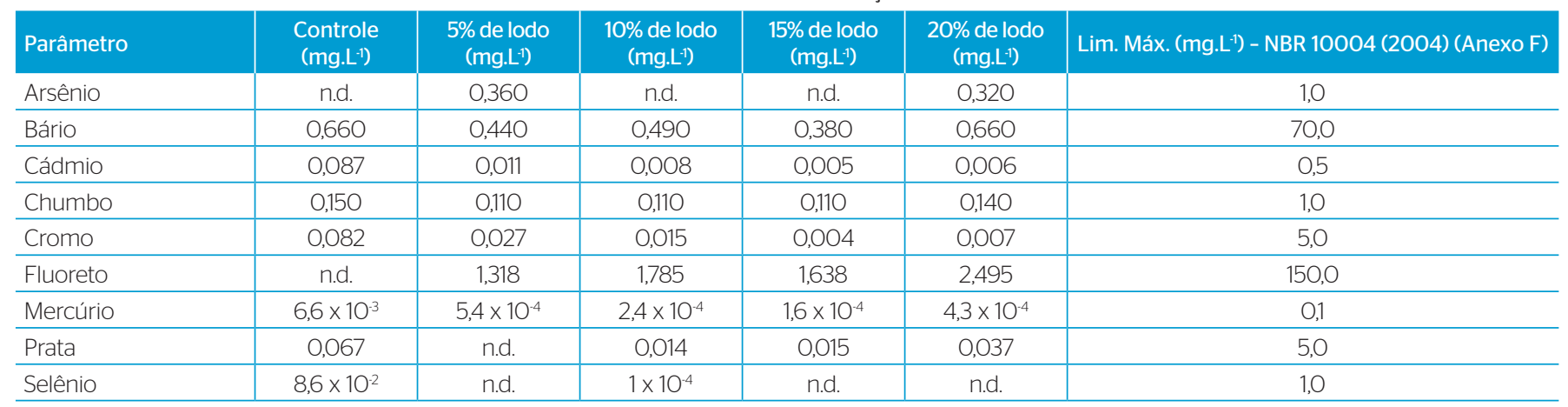

n.d.: não detectado.

Tabela 6 - Características tóxicas dos blocos cerâmicos acústicos (ensaio de solubilização).

\begin{tabular}{|c|c|c|c|c|c|c|}
\hline Parâmetro & $\begin{array}{l}\text { Controle } \\
\left.\text { (mg. } \mathrm{L}^{-1}\right)\end{array}$ & $\begin{array}{c}5 \% \text { de lodo } \\
\left.\text { (mg. } \mathrm{L}^{-1}\right)\end{array}$ & $\begin{array}{l}10 \% \text { de lodo } \\
\left(\mathrm{mg}^{\mathrm{L}} \mathrm{L}^{-1}\right)\end{array}$ & $\begin{array}{l}\text { 15\% de lodo } \\
\text { (mg..'-1) }\end{array}$ & $\begin{array}{c}20 \% \text { de lodo } \\
\left.\text { (mg. } \mathrm{L}^{-1}\right)\end{array}$ & Lim. Máx. (mg.L-1) - Anexo G da NBR 10004 (2004) \\
\hline Alumínio & 0,160 & 0,140 & 0,180 & 0,130 & 0,068 & 0,200 \\
\hline Arsênio & n.d. & n.d. & n.d. & n.d. & 0,010 & 0,010 \\
\hline Cádmio & $4 \times 10^{3}$ & $4 \times 10^{-4}$ & $2,18 \times 10^{-4}$ & $1,35 \times 10^{-4}$ & n.d. & 0,005 \\
\hline Chumbo & $7,99 \times 10^{-3}$ & $1,19 \times 10^{-3}$ & $7,8 \times 10^{-4}$ & $4,4 \times 10^{-4}$ & $4,6 \times 10^{-4}$ & 0,010 \\
\hline Cromo total & n.d. & n.d. & n.d. & n.d. & n.d. & 0,050 \\
\hline Ferro & n.d. & n.d. & n.d. & n.d. & n.d. & 0,300 \\
\hline Manganês & 0,051 & $9 \times 10^{-3}$ & 0,081 & 0,077 & 0,075 & 0,100 \\
\hline Mercúrio & $2,7 \times 10^{-4}$ & $2 \times 10^{-5}$ & $2 \times 10^{-5}$ & $4 \times 10^{-5}$ & $3 \times 10^{-5}$ & 0,001 \\
\hline Prata & 0,006 & 0,039 & 0,042 & 0,039 & 0,035 & 0,050 \\
\hline Zinco & 0,478 & 0,193 & 0,149 & 0,032 & 0,018 & 5,000 \\
\hline
\end{tabular}

n.d.: não detectado. 
incorporação de 5, 10, 15 e 20\% de lodo misto de lavanderia têxtil, permitiram comprovar a estabilização dos metais constituintes do resíduo na massa argilosa. Os resultados mostraram que as concentrações de metais nos extratos lixiviados e solubilizados dos blocos cerâmicos ficaram abaixo dos limites definidos pelos anexos F e G da NBR 10004 (2004) da ABNT.

Pelas análises de superfície utilizando a MEV foram notadas uma quantidade e uma variedade maiores de poros nos blocos cerâmicos confeccionados à medida que tais objetos foram fabricados com quantidade maior de lodo misto incorporado.
Os resultados permitem afirmar que o processo de S/E pode ser utilizado como forma de tratamento e aproveitamento dos resíduos gerados nas estações de tratamento de efluentes têxteis, uma vez que os produtos obtidos a partir dessa técnica apresentaram características físicas, mecânicas e toxicológicas em acordo com a legislação vigente. Para que se garanta a potencialidade de utilização desse processo na fabricação de blocos cerâmicos acústicos, deve-se proceder à avaliação da absorção de energia sonora, trabalho este já em desenvolvimento pelo grupo, cujos resultados serão publicados brevemente.

\section{REFERÊNCIAS}

ABNT - Associação Brasileira de Normas Técnicas. (1984) NBR 6459: Solo - Determinação do limite de liquidez. Rio de Janeiro: ABNT.

ABNT - Associação Brasileira de Normas Técnicas. (1984) NBR 6508: Grãos de solos que passam na peneira de 4,8 mm - Determinação da massa específica. Rio de Janeiro: ABNT.

ABNT - Associação Brasileira de Normas Técnicas. (1984) NBR 7180: Solo - Determinação do limite de plasticidade. Rio de Janeiro: ABNT.

ABNT - Associação Brasileira de Normas Técnicas. (1984) NBR 7181: Solo - Análise granulométrica. Rio de Janeiro: ABNT.

ABNT - Associação Brasileira de Normas Técnicas. (2004) NBR 10004: Resíduos Sólidos - Classificação. Rio de Janeiro: ABNT.

ABNT - Associação Brasileira de Normas Técnicas. (2004) NBR 10005: Procedimento para obtenção de extrato lixiviado de resíduos sólidos. Rio de Janeiro: ABNT.

ABNT - Associação Brasileira de Normas Técnicas. (2004) NBR 10006: Procedimento para obtenção de extrato solubilizado de resíduos sólidos. Rio de Janeiro: ABNT.

ABNT - Associação Brasileira de Normas Técnicas. (2005) NBR 152702: Componentes cerâmicos. Parte 2: Blocos cerâmicos para alvenaria estrutural - Terminologia e requisitos. Rio de Janeiro: ABNT.

ABNT - Associação Brasileira de Normas Técnicas. (2005) NBR 152703: Componentes cerâmicos. Parte 3: Blocos cerâmicos para alvenaria estrutural e de vedação - Métodos de ensaio. Rio de Janeiro: ABNT.

APHA - American Public Health Association. (2005) Standard methods for the examination water and wastewater. 21 ed. Washington: APHA. 1083 p.

BISTAFA, S.R. (2011) Acústica aplicada ao controle do ruído. 2 ed. rev. São Paulo: Edgard Blücher. 384 p.

CAMPOS, L.F.A.; MACEDO, R.S.; KIYOHARA, P.K.; FERREIRA, H.C. (1999) Características de plasticidade de argilas para uso em cerâmica vermelha ou estrutural. Revista Cerâmica, v. 45, n. 295, p. 140-145.

EMBRAPA - Empresa Brasileira de Pesquisa Agropecuária. (1997) Centro Nacional de Pesquisa de Solos. Manual de métodos de análise de solo. 2 ed. rev. atual. Rio de Janeiro: EMBRAPA. 212 p.

HEREK, L.C.S.; BERGAMASCO, R.; TAVARES, C.R.G. (2O10) Fabricação de blocos cerâmicos de vedação pela incorporação com lodo de lavanderia industrial. Revista Cerâmica, v. 56, n. 340, p. 389-392.
KAMINATA, O.T. (2008) Aproveitamento do lodo gerado no tratamento de efluente da indústria de lavanderia têxtil na produção de bloco de cerâmica vermelha. Dissertação (Mestrado em Engenharia Urbana) Universidade Estadual de Maringá, Maringá.

KIEHL. E.J. (1979) Manual de Edafologia: relação solo-planta. São Paulo: Ed. Agronômica Ceres. 262 p.

LISOT, A. (2008) Ressoadores de Helmholtz em barreiras acústicas: avaliação de desempenho na atenuação do ruído de tráfego. Dissertação (Mestrado em Engenharia Urbana) - Universidade Estadual de Maringá, Maringá.

MINERAIS DO PARANÁ S.A. (MINEROPAR). (2006) Rochas, minerais e minérios: argila. Disponível em: <http://www.pr.gov.br/mineropar/htm/ rocha/argila.html>. Acesso em: 20 fev. 2010.

MOREIRA, A.H.; OLIVEIRA, R.M.; LIMA, P.D.S. (2001) Efeito da adição do lodo de águas residuais da indústria têxtil nas propriedades de materiais de construção. Revista Cerâmica, v. 47, n. 303, p. 158-162.

OLIVEIRA, E.M.S.; MACHADO, S.Q.; HOLANDA, J.N.F. (2004) Caracterização de resíduo (lodo) proveniente de estação de tratamento de águas visando sua utilização em cerâmica vermelha. Revista Cerâmica, v. 50, n. 316, p. 324-330.

PAIXÃO, L.C.C.; YOSHIMURA, H.N.; ESPINOSA, D.C.R.; TENORIO, J.A.S. (2008) Efeito da incorporação de lodo de ETA contendo alto teor de ferro em cerâmica argilosa. Revista Cerâmica, v. 54 n. 329, p. 63-76.

SANTOS, J.L.P. dos. (2005) Estudo do potencial tecnológico de materiais alternativos em absorção sonora. Santa Maria: Editora da UFSM. 75 p.

SOUZA, L.C.L. de; ALMEIDA, M.G. de; BRAGANÇA, L. (2006) Bê-aba da acústica arquitetônica: ouvindo a arquitetura. São Carlos: EdUFSCar. $150 \mathrm{p}$.

THOMAS, G.W. (1996) Soil pH and soil acidity. In: SPARKS, D.L.; PAGE, A.L.; HELMKE, P.A.; LOEPPERT, R.H.; SOLTANPOUR, P.N.; TABATABAI, M.A.; JOHNSTON, C.T.; SUMNER, M.E. Methods of Soil Analysis. Part 3 Chemical Methods. Ed. Soil Science Society of America, Madison, WI, USA, n. 5, p. 475-490.

VIEIRA, C.M.F.; DIAS, C.A.C.M.; MOTHÉ, A.V.; SÁNCHEZ, R.; MONTEIRO, S.N. (2007) Incorporação de lama de alto forno em cerâmica vermelha. Revista Cerâmica, v. 53, n. 328, p. 381-387. 